\title{
Spinal navigation for posterior instrumentation of C1-2 instability using a mobile intraoperative CT scanner
}

\author{
*Marcus Czabanka, MD, Julien Haemmerli, MD,1 Nils Hecht, MD, ${ }^{1}$ Bettina Foehre, MD, ${ }^{3}$ \\ Klaus Arden, MD, ${ }^{3}$ Thomas Liebig, MD, ${ }^{2}$ Johannes Woitzik, MD, ${ }^{1}$ and Peter Vajkoczy, MD ${ }^{1}$ \\ Departments of ${ }^{1}$ Neurosurgery and ${ }^{3}$ Anesthesiology and Intensive Care Medicine; and ${ }^{2}$ Institute for Neuroradiology, Charité, \\ Campus Mitte, Berlin, Germany
}

\begin{abstract}
OBJECTIVE Spinal navigation techniques for surgical fixation of unstable C1-2 pathologies are challenged by complex osseous and neurovascular anatomy, instability of the pathology, and unreliable preoperative registration techniques. An intraoperative CT scanner with autoregistration of C-1 and C-2 promises sufficient accuracy of spinal navigation without the need for further registration procedures. The aim of this study was to analyze the accuracy and reliability of posterior C1-2 fixation using intraoperative mobile CT scanner-guided navigation.

METHODS In the period from July 2014 to February 2016, 10 consecutive patients with instability of C1-2 underwent posterior fixation using $\mathrm{C}-2$ pedicle screws and $\mathrm{C}-1$ lateral mass screws, and 2 patients underwent posterior fixation from $\mathrm{C}-1$ to $\mathrm{C}-3$. Spinal navigation was performed using intraoperative mobile CT. Following navigated screw insertion in C-1 and C-2, intraoperative CT was repeated to check for the accuracy of screw placement. In this study, the accuracy of screw positioning was retrospectively analyzed and graded by an independent observer.

RESULTS The authors retrospectively analyzed the records of 10 females and 2 males, with a mean age of $80.7 \pm$ 4.95 years (range 42-90 years). Unstable pathologies, which were verified by fracture dislocation or by flexion/extension radiographs, included 8 Anderson Type II fractures, 1 unstable Anderson Type III fracture, 1 hangman fracture Levine Effendi la, 1 complex hangman-Anderson Type III fracture, and 1 destructive rheumatoid arthritis of C1-2. In 4 patients, critical anatomy was observed: high-riding vertebral artery (3 patients) and arthritis-induced partial osseous destruction of the C-1 lateral mass (1 patient). A total of 48 navigated screws were placed. Correct screw positioning was observed in 47 screws (97.9\%). Minor pedicle breach was observed in 1 screw (2.1\%). No screw displacement occurred (accuracy rate $97.9 \%)$.
\end{abstract}

CONCLUSION Spinal navigation using intraoperative mobile CT scanning was reliable and safe for posterior fixation in unstable $\mathrm{C} 1-2$ pathologies with high accuracy in this patient series.

https://thejns.org/doi/abs/10.3171/2017.1.SPINE16859

KEY WORDS spinal navigation; C1-2 stabilization; intraoperative CT; craniocervical instability; cervical

$\mathrm{T}$ HE atlantoaxial junction is a highly complicated and specialized region of the cervical spine, allowing a large range of movement while maintaining spinal stability with diverse interactions with important neurovascular structures such as the vertebral arteries and the upper cervical spinal cord. 1,8,12,13,17,19,21,23,24,28,33-35 Fractures, tumors, congenital deformities, or inflammatory processes at this level lead to instability, which imposes a signifi- cant risk to the associated neurovascular structures. ${ }^{7,8,12,13,}$ 17,18,21,24,28,29,33,35 For example, unstable odontoid fractures are common conditions in elderly patients after traumatic injuries, leading to permanent deficits, at worst to tetraparesis or death if the patient is not surgically stabilized.,4, 9,12,20,27 Different ventral and dorsal surgical strategies are available to stabilize unstable atlantoaxial pathologies. Dorsal strategies are characterized by superior bio-

ABBREVIATIONS HRVA = high-riding vertebral artery

SUBMITTED July 20, 2016. ACCEPTED January 17, 2017.

INCLUDE WHEN CITING Published online June 9, 2017; DOI: 10.3171/2017.1.SPINE16859.

* Drs. Czabanka and Haemmerli contributed equally to this work. 

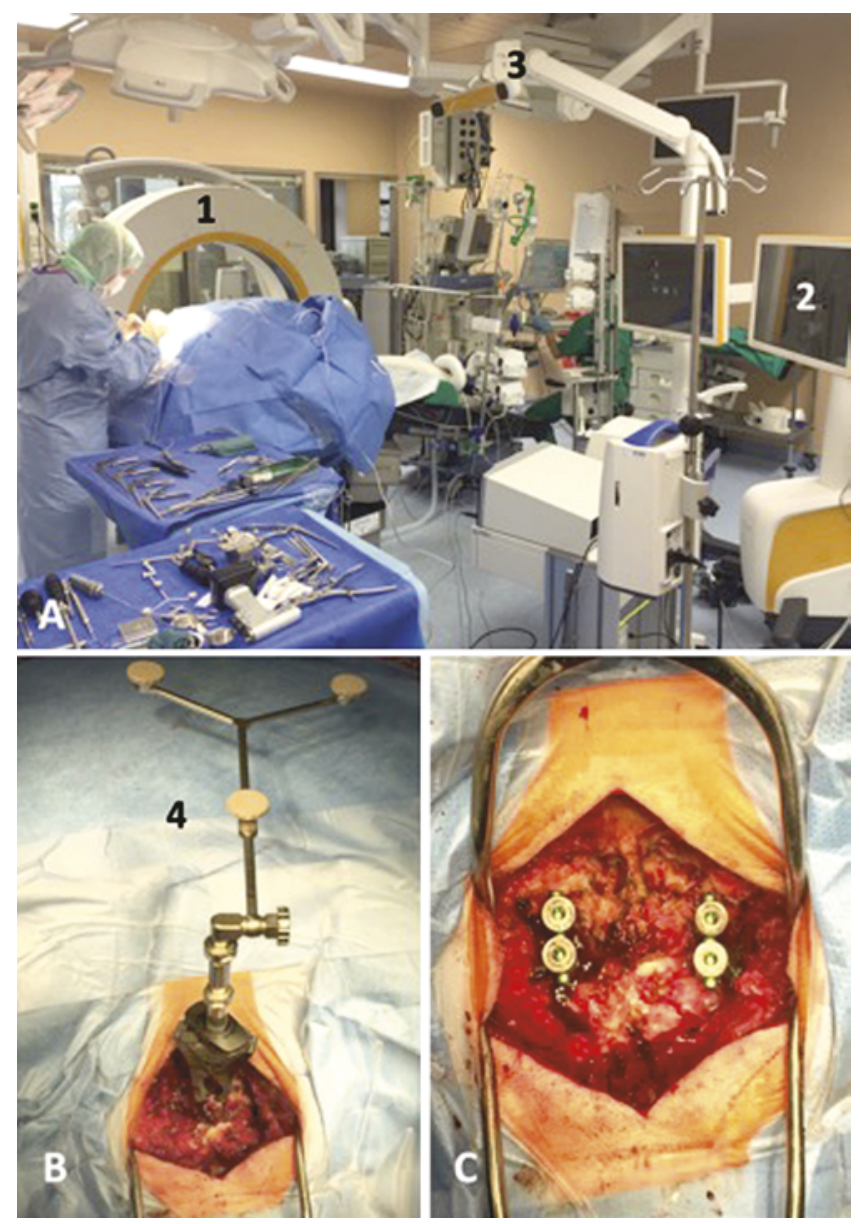

FIG. 1. A: Configuration of the AIRO CT scanner setup in the operating theater before registration: 1, AIRO CT scanner; 2, screens for 3D reconstruction; 3 , intraoperative camera for registration and navigation. B: Navigation tracking device (4) over C-2. C: Postspondylodesis C1-2, according to Harm's description. Figure is available in color online only.

mechanical stability; ${ }^{12,13,229}$ however, they suffer from an increased risk of vertebral artery injury compared with ventral stabilization techniques. Previous studies have reported a vertebral artery injury rate ranging from $0 \%$ to $8.2 \% 24,36$ in clinical studies and up to $26 \%$ in cadaveric studies. $^{22}$ The most common dorsal stabilization techniques are the atlantoaxial transarticular screw technique described by Jeanneret and Mager ${ }^{13}$ and the C-1 lateral mass/C-2 pedicle screw-rod technique described by Harms and Melcher. ${ }^{8}$ To reduce the risk of neurovascular injury, spinal navigation techniques are frequently used to perform dorsal stabilization of the atlantoaxial junction. Current techniques include the use of an intraoperative 3D fluoroscopy system aiming for autoregistration of the C1-2 segment or preoperative navigation CT scanning with subsequent surface matching to navigate the $\mathrm{C} 1-2$ segment. ${ }^{2,5,7,11,16,19,26,30,32}$ Three-dimensional fluoroscopy systems suffer from an inaccurate registration process that imposes significant risk to cervical applications., ${ }^{5,34}$ Preoperative navigation $\mathrm{CT}$, which is usually performed with the patient supine, may be critical as the unstable pathol- ogy usually leads to different spinal alignment once the patient is positioned prone for surgery. Moreover, surface matching of C-1 is hindered by a reduced osseous surface of $\mathrm{C}-1$ and the deep screw entry point on the lateral mass of $\mathrm{C}-1$. Using an intraoperative $\mathrm{CT}$ scanner promises to overcome these drawbacks by allowing navigation CT after positioning and reducing the $\mathrm{C} 1-2$ segment while at the same time allowing autoregistration of C-1 and C-2. The purpose of this study was to evaluate the feasibility and accuracy of intraoperative CT-guided 3D navigation of the atlantoaxial junction for dorsal C1-2 stabilization using C-1 lateral mass screws and $\mathrm{C}-2$ pedicle screws in unstable and complex $\mathrm{C} 1-2$ pathologies.

\section{Methods \\ Patient Population}

Between July 2014 and February 2016, 12 consecutive patients with $\mathrm{Cl}-2$ instability were treated with navigated dorsal stabilization using the mobile intraoperative $\mathrm{CT}$ scanner AIRO (BrainLab AG). Every patient presented with an unstable $\mathrm{C} 1-2$ junction (for example, displaced dens fracture) on the preoperative CT scan. Instability was additionally verified with flexion/extension radiographs if needed.

After surgery, patients were scheduled for an appointment in our outpatient department to undergo clinical follow-up examination 1 month after surgery.

\section{Surgical Technique}

In all patients, $\mathrm{C}-1$ lateral mass screws and $\mathrm{C}-2$ pedicle screws were placed to stabilize the C1-2 segment. In 2 patients, additional fixation of the $\mathrm{C} 2-3$ segment was performed using lateral mass screws. The complete surgical procedure was performed according to the previously published description of navigated spinal instrumentation using the mobile intraoperative CT scanner AIRO (Fig. 1). ${ }^{10}$ Each patient was placed prone on the carbon fiber surgical table (TruSystem 7500, Trumpf Medical Inc.) with the head fixed with a Mayfield clamp (Trumpf XRAY, Trumpf Medical Inc.). Unstable pathology of C1-2 was reduced using traction and restoration and/or inclination via the Mayfield clamp to restore the physiological configuration of the C1-2 pathology (Fig. 2). After surgical exposure, the navigation tracking device (BrainLab AG) was placed on the spinous process of C-2 (Fig. 1). The first CT scan was obtained to allow autoregistration for spinal navigation and $3 \mathrm{D}$ reconstruction of the upper cervical spine. To verify registration accuracy, meticulous intraoperative control of anatomical landmarks was performed. Following the verification of accuracy, C-1 lateral mass screws and C-2 pedicle screws were placed. For this purpose, a precalibrated drill guide (BrainLab AG) was used. In all cases (including the C-1 lateral mass screws), the navigated screw trajectory was opened with a sharp drill (Stryker cordless driver) to reduce pressure on the unstable C1-2 segment (Fig. 3). A guidewire was placed, and cannulated screws (Ulrich Neon, Ulrich $\mathrm{GmbH}$ ) were inserted using the guidewire as a trajectory control. Lateral mass screws in C-3 were placed according to anatomical landmarks. After screw placement, a second intraoperative CT scan was obtained to verify 


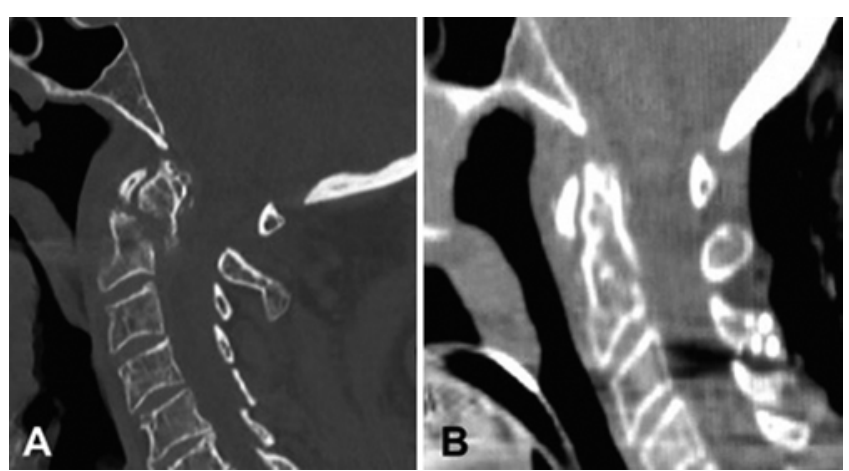

FIG. 2. Difference in C1-2 configuration between preoperative CT (A) showing displacement of the C-2 fracture (displaced Anderson Type II fracture) and intraoperative CT (B) after reduction of C1-2 displacement.

screw positioning. All CT scans were obtained under apnea ventilation following preoxygenation to avoid any motion artifact.

\section{Anatomical Analysis}

All patients underwent cervical CT on admission. The diameter of the pedicle of the axis as well as the distance between the vertebral canal and the spinal canal at the C-1 level was retrospectively measured. The $\mathrm{C}-2$ pedicle diameter was defined as the minimum width ventral to the inferior articular facet of C-2 and dorsal to the superior articular facet.

\section{Assessment of Screw Positioning}

The second intraoperative CT scan was used to analyze screw positioning in a retrospective fashion. An independent observer retrospectively graded screw positioning according to a previously described classification system for the cervical spine. ${ }^{25}$ Screws that were placed completely within the pedicle were defined as correctly placed (Grade $0)$. Minor pedicle perforations were defined as a pedicle breach $<2 \mathrm{~mm}$ (Grade 1). Misplaced screws were defined as a pedicle perforation $>2 \mathrm{~mm}$ (Grades 3 and 4). Additionally, the bicortical placement of screws was assessed. Bicortical placement was defined as perforation of the distant cortical bone on sagittal and axial CT scans. Bicortical perforation $>5 \mathrm{~mm}$ was defined as misplacement.

\section{Results}

\section{Pathology of the C1-2 Segment}

The following pathologies were treated: Anderson Type II fracture (8 patients), hangman fracture Levine Effendi Ia with spondylolisthesis more than $4 \mathrm{~mm}$ (1 patient), unstable Anderson Type III fracture (1 patient), complex dislocated hangman-Anderson Type III fracture (1 patient), and rheumatoid arthritis-induced instability of the C1-2
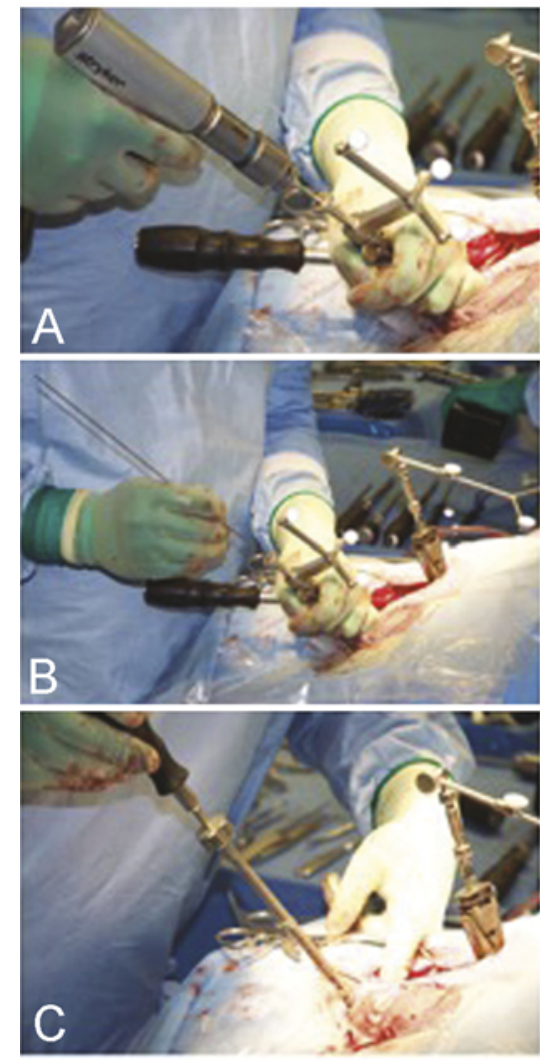
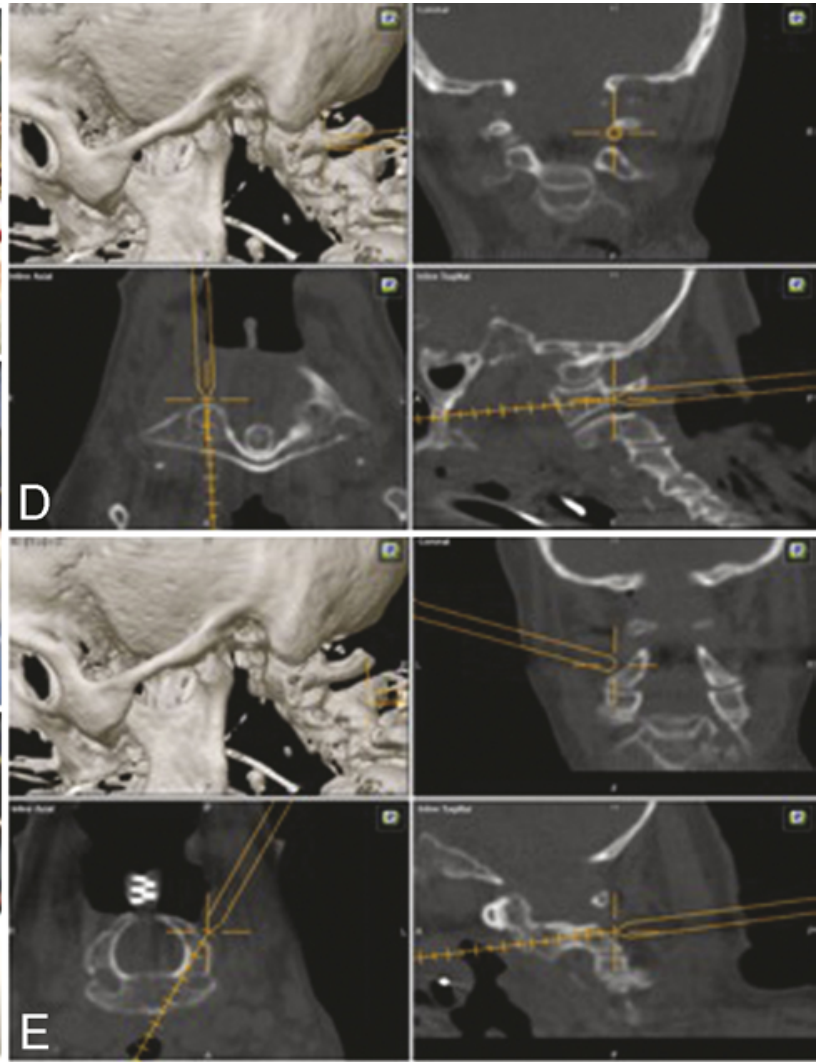

FIG. 3. Drill with its navigated drill guide (A). Guidewire to test the drill hole and control insertion of the cannulated screws (B). Screwdriver inserting screws along the guidewire (C). Intraoperative CT scans after registration: planning the C-1 lateral mass screws (D) and planning the C-2 screws (E). Figure is available in color online only. 
TABLE 1. Summary of characteristics in 12 patients with C1-2 injury

\begin{tabular}{|c|c|c|c|c|c|c|c|c|c|c|}
\hline $\begin{array}{l}\text { Case } \\
\text { No. }\end{array}$ & $\begin{array}{l}\text { Age/ } \\
\text { Sex }\end{array}$ & $\begin{array}{l}\text { Preop } \\
\text { Findings }\end{array}$ & $\begin{array}{l}\text { Preop } \\
\text { Deficit }\end{array}$ & $\begin{array}{l}\text { Mechanism } \\
\text { of Injury }\end{array}$ & HRVA & Surgery & $\begin{array}{l}\text { iCT Pre- } \\
\text { \& Post- } \\
\text { Screw }\end{array}$ & $\begin{array}{l}\text { Screw } \\
\text { Revision }\end{array}$ & $\begin{array}{c}\text { Time of } \\
\text { Surgery } \\
\text { (hrs:mins) }\end{array}$ & $\begin{array}{l}\mathrm{FU} \\
1 \mathrm{Mo}\end{array}$ \\
\hline 1 & $88 / F$ & $\begin{array}{l}\text { And II, no } \\
\text { dislocation, no } \\
\text { myelopathy }\end{array}$ & None & Fell from height & No & C-1 BCs, C-2 BCs & $\begin{array}{l}\text { Satisfac- } \\
\text { tory }\end{array}$ & No & $02: 30$ & $\begin{array}{l}\text { No deficit, } \\
\text { screws } \\
\text { satisfactory }\end{array}$ \\
\hline 2 & $85 / F$ & $\begin{array}{l}\text { And III, C-2 body } \\
\text { fracture, no dislo- } \\
\text { cation, instability, } \\
\text { no myelopathy }\end{array}$ & None & $\begin{array}{l}\text { Fell from } 5 \\
\text { steps }\end{array}$ & No & C-1 BCs, C-2 BCs & $\begin{array}{l}\text { Satisfac- } \\
\text { tory }\end{array}$ & No & 03:30 & $\begin{array}{l}\text { No deficit, } \\
\text { screws } \\
\text { satisfactory }\end{array}$ \\
\hline 3 & $83 / F$ & $\begin{array}{l}\text { And II, C1-2 } \\
\text { dislocation, } \\
\text { myelopathy C-2 }\end{array}$ & None & Fell from height & Yes & $\begin{array}{c}\text { C-1 BCs; C-2: BC } \\
\text { rt, MC It; C-3 lat } \\
\text { mass screws }\end{array}$ & $\begin{array}{l}\text { Satisfac- } \\
\text { tory }\end{array}$ & No & $02: 45$ & $\begin{array}{l}\text { No deficit, } \\
\text { screws } \\
\text { satisfactory }\end{array}$ \\
\hline 4 & $90 / F$ & $\begin{array}{l}\text { And II, no } \\
\text { dislocation, no } \\
\text { myelopathy }\end{array}$ & None & Fell from height & No & $\mathrm{C}-1 \mathrm{BCs}, \mathrm{C}-2 \mathrm{BCs}$ & $\begin{array}{l}\text { Satisfac- } \\
\text { tory }\end{array}$ & No & $02: 10$ & $\begin{array}{l}\text { No deficit, } \\
\text { screws } \\
\text { satisfactory }\end{array}$ \\
\hline 5 & $83 / F$ & $\begin{array}{l}\text { And II, dislocation, } \\
\text { C-1 fracture }\end{array}$ & None & Fell from height & No & C-1 BCs, C-2 BCs & $\begin{array}{l}\text { Satisfac- } \\
\text { tory }\end{array}$ & No & $02: 55$ & $\begin{array}{l}\text { No deficit, } \\
\text { screws } \\
\text { satisfactory }\end{array}$ \\
\hline 6 & $42 / \mathrm{M}$ & $\begin{array}{l}\text { And II old, pseud- } \\
\text { arthrosis, C1-2 } \\
\text { dislocation }\end{array}$ & Tetraparesis & Car accident & No & C-1 BCs, C-2 BCs & $\begin{array}{l}\text { Satisfac- } \\
\text { tory }\end{array}$ & $\begin{array}{l}\text { No, left w/ } \\
\text { breach } \\
\text { into the } \\
\text { VC }\end{array}$ & 01:53 & $\begin{array}{l}\text { No deficit, } \\
\text { screws } \\
\text { satisfactory }\end{array}$ \\
\hline 7 & $90 / F$ & $\begin{array}{l}\text { And II, no } \\
\text { dislocation, no } \\
\text { myelopathy }\end{array}$ & None & Fell from height & No & C-1 BCs, C-2 BCs & $\begin{array}{l}\text { Satisfac- } \\
\text { tory }\end{array}$ & No & $02: 10$ & $\begin{array}{l}\text { No deficit, } \\
\text { screws } \\
\text { satisfactory }\end{array}$ \\
\hline 8 & $70 / \mathrm{M}$ & $\begin{array}{l}\text { Hangman Levine la, } \\
\text { no dislocation, } \\
\text { no myelopathy }\end{array}$ & None & $\begin{array}{l}\text { Fell while under } \\
\text { influence of } \\
\text { alcohol }\end{array}$ & Yes & $\begin{array}{l}\text { C-1 BCs; C-2: BC } \\
\text { It, MC rt }\end{array}$ & $\begin{array}{l}\text { Satisfac- } \\
\text { tory }\end{array}$ & No & $03: 40$ & $\begin{array}{l}\text { No deficit, } \\
\text { screws } \\
\text { satisfactory }\end{array}$ \\
\hline 9 & $90 / F$ & $\begin{array}{l}\text { And II, no } \\
\text { dislocation, no } \\
\text { myelopathy }\end{array}$ & None & Fell from height & No & C-1 BCs, C-2 BCs & $\begin{array}{l}\text { Satisfac- } \\
\text { tory }\end{array}$ & No & $02: 30$ & $\begin{array}{l}\text { No deficit, } \\
\text { screws } \\
\text { satisfactory }\end{array}$ \\
\hline 10 & $76 / F$ & $\begin{array}{l}\text { Rheumatoid arthri- } \\
\text { tis, } \mathrm{C} 1-2 \text { partial } \\
\text { destruction }\end{array}$ & $\begin{array}{l}\text { Limitation of } \\
\text { range of } \\
\text { movement }\end{array}$ & Inflammatory & No & C-1 BCs, C-2 BCs & $\begin{array}{l}\text { Satisfac- } \\
\text { tory }\end{array}$ & No & $2: 45$ & $\begin{array}{l}\text { No deficit, } \\
\text { screws } \\
\text { satisfactory }\end{array}$ \\
\hline 11 & $90 / F$ & $\begin{array}{l}\text { And II, no } \\
\text { dislocation, no } \\
\text { myelopathy }\end{array}$ & None & Fell from height & Yes & C-1 BCs, C-2 MCs & $\begin{array}{l}\text { Satisfac- } \\
\text { tory }\end{array}$ & $\begin{array}{c}\text { No, epidural } \\
\text { bleeding }\end{array}$ & 03:30 & $\begin{array}{l}\text { No deficit, } \\
\text { screws } \\
\text { satisfactory }\end{array}$ \\
\hline 12 & $81 / F$ & $\begin{array}{l}\text { Complex hangman- } \\
\text { And III }\end{array}$ & Myoclony & Fell from height & No & $\begin{array}{l}\text { C-1 BCs, C-2 } \\
\text { BCs, C-3 lat } \\
\text { mass screws }\end{array}$ & $\begin{array}{l}\text { Satisfac- } \\
\text { tory }\end{array}$ & No & $02: 40$ & $\begin{array}{l}\text { No deficit, } \\
\text { screws } \\
\text { satisfactory }\end{array}$ \\
\hline Total & $\begin{array}{l}\text { Mean } \\
\text { age: } \\
80.7\end{array}$ & & & & $\begin{array}{r}\text { HVRA: } \\
25 \%\end{array}$ & & $100 \%$ & & $\begin{array}{l}\text { Mean } \\
\text { time: } \\
02: 45\end{array}$ & $100 \%$ \\
\hline
\end{tabular}

And II = Anderson fracture type II; BC = bicortical screw; FU = follow-up; hangman = hangman fracture; Levine = Levine Effendi; $\mathrm{MC}=$ monocortical screw; iCT = intraoperative $\mathrm{CT} ; \mathrm{VC}=$ vertebral canal.

segment with compression of the cervical spinal cord (1 patient; Table 1). Four of these patients presented with anatomical variations imposing additional challenges for surgery: 3 had a high-riding vertebral artery (HRVA), and 1 had partial arthritis-induced destruction of the C-1 lateral mass bilaterally.

\section{Patient Population}

Ten female and 2 male patients, with a mean age of 80.7 \pm 4.95 years, were analyzed in our study. Eleven patients suffered from cervical trauma, while 1 patient was diagnosed with rheumatoid arthritis-induced instability of the atlantoaxial junction (Table 1). One patient demonstrated tetraparesis (proximal M2/5 and distal M4/5, according to the British Medical Research Council scale), whereas the remaining 11 patients had no preoperative neurological deficit. All patients complained about neck pain without radicular pain. 
TABLE 2. Placement of the navigated screws using AIRO

\begin{tabular}{lclc}
\hline \multicolumn{1}{c}{ Parameter } & C-1 (\%) & C-2 (\%) & Total (\%) \\
\hline No. of screws & $24(50)$ & $24(50)$ & $48(100)$ \\
\hline Correct placement of the screws & $24(100)$ & $23(95.8)$ & $47(97.9)$ \\
\hline Bicortical screws & $24(100)$ & $20(83.3)$ & $44(91.7)$ \\
\hline Minimal pedicle breach & $0(0)$ & $1(4.2)$ & $1(2.1)$ \\
\hline Screw displacement & $0(0)$ & $0(0)$ & $0(0)$ \\
\hline Intraop screw revision & $0(0)$ & $0(0)$ & $0(0)$ \\
\hline Vertebral artery injury & $0(0)$ & $0(0)$ & $0(0)$ \\
\hline
\end{tabular}

The C-3 screws were not included in the analysis as they were not placed using intraoperative navigation.

Mean diameter of the C-2 pedicle was $4.6 \mathrm{~mm}$ (SD 1.4), and the mean distance between the vertebral canal and the spinal canal of C-1 was $9.4 \mathrm{~mm}$ (SD $1.8 \mathrm{~mm}$ ).

Surgical indication was based on a preoperative cervical CT scan and/or MR image in all patients. In 3 patients, an HRVA was verified with vascular diagnostics (MR angiography or CT angiography). In 1 patient, partial destruction of the lateral mass of $\mathrm{C}-1$ was verified with a CT scan.

\section{Accuracy of Surgical Technique and Mobile CT-Guided Spinal Navigation}

In all patients, 2 intraoperative CT scans per surgery (1 navigation and 1 control scan) were obtained (a total of 24 CT scans in the study). Autoregistration was accurate and image quality was good in every case. No additional scans had to be obtained to improve navigation accuracy.

A total of 48 screws were placed using navigation (C-3 screws were placed in a freehand technique based on anatomical landmarks): $24 \mathrm{C}-1$ lateral mass screws, $24 \mathrm{C}-2$ pedicle screws (20 C-2 pedicle screws, 4 C-2 pars screws). Twenty-three C-2 pedicle screws had a diameter of $4 \mathrm{~mm}$, and one $3.5-\mathrm{mm}$ screw was placed in 1 patient. All C-1 lateral mass screws had a diameter of $4 \mathrm{~mm}$. The C-3 lateral mass screws had a diameter of $3.5 \mathrm{~mm}$.

A total of 47 screws were placed correctly within the pedicle or the lateral mass of C-1 or C-2 (97.9\%). One screw showed minor left-sided perforation of the left C-2 pedicle (2.1\%). No screw misplacement $>2 \mathrm{~mm}$ was observed (Table 2). No compression or lesion of the neurovascular structures due to screw misplacement was identified. Revision of screw positioning was not necessary within this surgical series.

Bicortical placement was achieved for all C-1 screws (24 of 24) as well as for $20 \mathrm{C}-2$ screws (20 of 24). Because of HRVAs, short C-2 screws were intentionally placed with monocortical positioning (4 of 24) to avoid vascular injury (Table 2). The C-3 lateral mass screws were placed bicortically in all patients who underwent additional stabilization. The mean surgical time was 2.75 hours (range 1.88-3.67 hours; Table 1).

\section{Illustrative Case}

A 76-year-old female had been complaining for years about neck pain with radiation to the occipital skull and pain while turning her head as well as severe limitation in the range of movement in neck rotation. Her history was positive for rheumatoid arthritis. Imaging of the neck showed partial destruction of the dens with a posterior pannus narrowing the spinal canal at $\mathrm{C} 1-2$. The patient was mobile and presented with only minor signs of spinal ataxia. The CT scan demonstrated partial destruction of the C-1 lateral mass bilaterally (Fig. 4). To stabilize the C1-2 segment, the decision was made to use CT-guided navigation to overcome the anatomical drawbacks for posterior C-1 lateral mass screw and C-2 pedicle screw fixation. Intraoperative $\mathrm{CT}$ after screw placement was used as an immediate check, demonstrating highly accurate placement of the navigated screws. In particular, the $\mathrm{C}-1$ lateral mass screw on the right side exactly penetrated the bony bridge along the $\mathrm{C}-1$ lateral mass.

\section{Discussion}

In this surgical series, the safety, accuracy, and efficacy of mobile intraoperative CT-guided autoregistration for spinal navigation of unstable $\mathrm{C} 1-2$ pathologies were demonstrated. Posterior instrumentation of the C1-2 segment is regarded as a complex procedure given the high risk for vascular or neurological injury. ${ }^{8,12,13,17,21,24,28,29,33,35}$ Injury to the vertebral artery has been reported to range between $0 \%$ and $8.2 \%{ }^{24}$ for posterior fixation techniques. Spinal navigation procedures promise to reduce the risk of posterior instrumentation techniques; $2,5,7,16,19,26,30,32,37$ however, different navigation strategies suffer from inaccurate registration because of technical drawbacks and the instability of the pathology. ${ }^{5,34}$ Applying intraoperative CT for navigation strategies may overcome these drawbacks since referencing is performed after positioning and reducing the unstable $\mathrm{C} 1-2$ pathology and thus improving accuracy. Moreover, accurate autoregistration makes surface matching for reference purposes unnecessary, allowing navigated screw insertion in the lateral mass of C-1 without additional manipulation (Fig. 4). Applying the abovedescribed surgical technique, we demonstrated highly accurate screw positioning for navigated placement of both C-1 and C-2 screws despite complicated anatomy. Computed tomography guidance has been shown to reduce screw misplacement in recent reports, which document a breach rate of up to $25 \%$, with $9 \%$ described as critical breaches with compression of the vertebral artery. ${ }^{14} \mathrm{Kim}$ et al. documented an $8.6 \%$ rate of noncritical breaches and $10.3 \%$ critical breaches ${ }^{15}$ Most pedicle breaches have been observed for C-2 pedicle screws. More recently, Ling et al. reported a $2 \%$ rate of pedicle breaches with the use of fully fixed intraoperative CT. ${ }^{19}$ In our series, the breach rate was only $2.1 \%$ using mobile CT technology for navigation (that is, 1 screw among 48). Moreover, mobile intraoperative $\mathrm{CT}$ allowed us to tailor the screw diameter and screw length to the individual anatomical characteristics to maximize screw strength as mostly $4-\mathrm{mm}$ cannulated screws were used in $\mathrm{C}-2$ pedicles with a mean diameter of $4.6 \mathrm{~mm}$.

Direct CT-guided registration after patient positioning and the adapted surgical technique using sharp drillguided opening of the screw trajectory with subsequent 


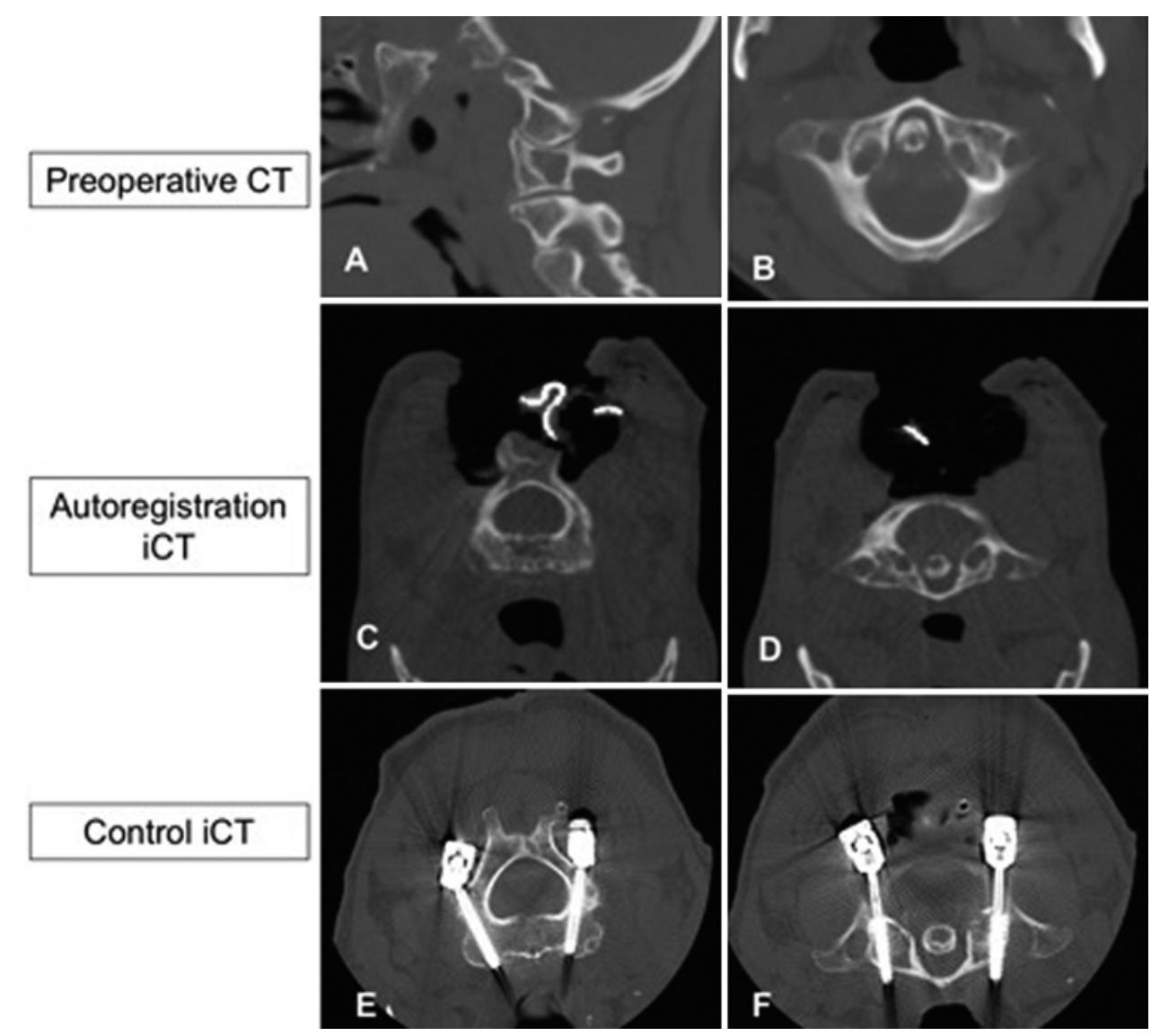

FIG. 4. Preoperative diagnostic sagittal (A) and axial (B) scans. Correct configuration of C-2 (C) with lytic partial destruction of C-1 lateral mass bilaterally. Intraoperative navigation CT scan (D). Intraoperative control CT scans after stabilization of C-2 (E) and C-1 (F) showing correct placement of the C-2 screws and the C-1 screws along the intact osseous bridge.

direct placement of the screws may represent factors that influenced screw accuracy in our study. Moreover, placement of the registration device on C-2 may be another factor explaining the low rate of pedicle breaches for the C-2 screws as navigation inaccuracy may be reduced to a minimum with this approach. We did not observe vertebral artery injuries in our small surgical series, which was performed after the initial learning curve with intraoperative CT-guided spinal navigation..$^{10}$ Because the vertebral arteries may have anatomical variability among patients, their lesion during the surgical procedure can be dramatic, ${ }^{21,24,35}$ leading to uncontrolled hemorrhage, cerebrovascular insufficiency, or neurological deficits. Wakao et al. prospectively analyzed $480 \mathrm{CT}$ angiography studies of Japanese patients. ${ }^{35}$ Fourteen percent of them showed vertebral artery variability, with more than $10 \%$ showing HRVAs. In the present study, 3 patients presented with an HRVA, which was diagnosed on CT angiography and MRI with vascular reconstruction. In 1 patient with HRVA, the surgical strategy was changed because navigation could not verify a safe screw trajectory without injuring the vertebral artery; therefore, short C-2 pars screws were placed instead. However, this technique remains uncertain regarding stability of the arthrodesis. ${ }^{29}$ In a cadaveric study, Du et al. analyzed the biomechanical difference between $\mathrm{C}-2$ pars screws and $\mathrm{C}-2$ pedicle screws after $\mathrm{C} 1-2$ arthrodesis and concluded that the $\mathrm{C}-2$ pedicle screws have twice the pullout strength of the C-2 pars screws. ${ }^{6}$ In the case of reliable spinal navigation, the C-2 short screws may be reserved for cases in which anatomical landmarks do not allow the placement of $\mathrm{C}-2$ pedicle screws. An important aspect for posterior C1-2 fixation using C-1 lateral mass screws and $\mathrm{C}-2$ pedicle screws is the bicortical placement of screws. ${ }^{34}$ We did observe bicortical placement of all screws that were placed with the intention of bicortical perforation. There currently exists no definition for misplaced bicortical screws in terms of too-long perforation of the ventral cortical bone; therefore, we used a randomly chosen definition of $>5 \mathrm{~mm}$ to define misplacement in our study. In this regard, cortical perforation was measured on axial and sagittal reconstructed CT scans that were intraoperatively obtained as control scans. None of the placed screws had to be revised because of misplaced bicortical perforation.

A limitation of the surgical strategy proposed herein may include extension of the surgical time. ${ }^{31}$ Although 2 intraoperative scans are required for the proposed surgical technique, the mean surgical time was 2.75 hours (range 1.88-3.67 hours). In a case series of 7 patients, Smith et al. documented a mean operative time of 188.7 minutes (3 hours, 8 minutes) ${ }^{31}$ The surgeon is responsible for the accuracy of the navigation system at all times. Consequently, 
regular control of the navigation system based on anatomical landmarks and surgical experience is required to detect navigation inaccuracies to prevent deception by the navigation system. Special care should be applied to correct fixation of the C-2 spinous process and to prevent manipulation of the reference in order to guarantee high accuracy rates. Pressure may be applied to the unstable pathology by drilling and placing the screws, which may dislocate the osseous structures and thereby contribute to navigation inaccuracy. Moreover, mobility of the cervical spine itself may represent a factor in navigational inaccuracy. These drawbacks are overcome by working with navigated sharp drilling techniques and cutting screws to reduce pressure on the unstable segment as much as possible. Placing the reference over the spinous process of $\mathrm{C}-2$ is considered to limit drawbacks caused by mobility of the cervical spine. Nevertheless, this surgical strategy relies on the accuracy of the intraoperative CT scan, the navigation system, and surgical expertise in working with sharp drilling and cutting screws to prevent risks of injury to the neurovascular structures.

\section{Conclusions}

Spinal navigation using intraoperative mobile CT guidance was reliable and safe for posterior fixation in unstable C1-2 pathologies with high accuracy in this patient series.

\section{Acknowledgments}

We thank our surgical team, especially Julia Heise and Franziska Köhler, for assistance during collection of the technical data. Marcus Czabanka was funded by the BIH Clinical Fellow Program.

\section{References}

1. Anderson LD, D'Alonzo RT: Fractures of the odontoid process of the axis. 1974. J Bone Joint Surg Am 86-A:2081, 2004

2. Attia W, Orief T, Almusrea K, Alfawareh M, Soualmi L, Orz Y: Role of the O-arm and computer-assisted navigation of safe screw fixation in children with traumatic rotatory atlantoaxial subluxation. Asian Spine J 6:266-273, 2012

3. Bourghli A, Luc S, Obeid I, Guérin P, Gille O, Vital JM, et al: Management of a major atlanto-axial instability secondary to a lytic lesion of C2. Eur Spine J 24:180-184, 2015

4. Bowers CA, Jost GF, Dailey AT: An odontoid fracture causing apnea, cardiac instability, and quadriplegia. Case Rep Crit Care 2012:821565, 2012

5. Bredow J, Oppermann J, Kraus B, Schiller P, Schiffer G, Sobottke R, et al: The accuracy of 3D fluoroscopy-navigated screw insertion in the upper and subaxial cervical spine. Eur Spine J 24:2967-2976, 2015

6. Du JY, Aichmair A, Kueper J, Wright T, Lebl DR: Biomechanical analysis of screw constructs for atlantoaxial fixation in cadavers: a systematic review and meta-analysis. J Neurosurg Spine 22:151-161, 2015

7. Engler JA, Smith ML: Use of intraoperative fluoroscopy for the safe placement of C2 laminar screws: technical note. Eur Spine J 24:2771-2775, 2015

8. Harms J, Melcher RP: Posterior C1-C2 fusion with polyaxial screw and rod fixation. Spine (Phila Pa 1976) 26:2467-2471, 2001

9. Harrop JS: Type II odontoid fractures: what to do? World Neurosurg 80:313-314, 2013

10. Hecht N, Kamphuis M, Czabanka M, Hamm B, König S,
Woitzik J, et al: Accuracy and workflow of navigated spinal instrumentation with the mobile $\mathrm{AIRO}^{\circledR} \mathrm{CT}$ scanner. Eur Spine J 25:716-723, 2016

11. Holly LT, Bloch O, Johnson JP: Evaluation of registration techniques for spinal image guidance. J Neurosurg Spine 4:323-328, 2006

12. Huang DG, Hao DJ, He BR, Wu QN, Liu TJ, Wang XD, et al: Posterior atlantoaxial fixation: a review of all techniques. Spine J 15:2271-2281, 2015

13. Jeanneret B, Magerl F: Primary posterior fusion $\mathrm{C} 1 / 2$ in odontoid fractures: indications, technique, and results of transarticular screw fixation. J Spinal Disord 5:464-475, 1992

14. Kast E, Mohr K, Richter HP, Börm W: Complications of transpedicular screw fixation in the cervical spine. Eur Spine J 15:327-334, 2006

15. Kim SU, Roh BI, Kim SJ, Kim SD: The clinical experience of computed tomographic-guided navigation system in C1-2 spine instrumentation surgery. J Korean Neurosurg Soc 56:330-333, 2014

16. Lang Z, Tian W, Liu Y, Liu B, Yuan Q, Sun Y: Minimally invasive pedicle screw fixation using intraoperative 3-dimensional fluoroscopy-based navigation (CAMISS Technique) for hangman fracture. Spine (Phila Pa 1976) 41:39-45, 2016

17. Lee SH, Park DH, Kim SD, Huh DS, Kim KT: Analysis of 3 -dimensional course of the intra-axial vertebral artery for C2 pedicle screw trajectory: a computed tomographic study. Spine (Phila Pa 1976) 39:E1010-E1014, 2014

18. Levine AM, Edwards CC: The management of traumatic spondylolisthesis of the axis. J Bone Joint Surg Am 67:217226, 1985

19. Ling JM, Tiruchelvarayan R, Seow WT, Ng HB: Surgical treatment of adult and pediatric $\mathrm{C} 1 / \mathrm{C} 2$ subluxation with intraoperative computed tomography guidance. Surg Neurol Int 4 (Suppl 2):S109-S117, 2013

20. Löhrer L, Raschke MJ, Thiesen D, Hartensuer R, Surke C, Ochman S, et al: Current concepts in the treatment of Anderson Type II odontoid fractures in the elderly in Germany, Austria and Switzerland. Injury 43:462-469, 2012

21. Maki S, Koda M, Iijima Y, Furuya T, Inada T, Kamiya K, et al: Medially-shifted rather than high-riding vertebral arteries preclude safe pedicle screw insertion. J Clin Neurosci 29:169-172, 2016

22. Meng XZ, Xu JX: The options of C2 fixation for os odontoideum: a radiographic study for the $\mathrm{C} 2$ pedicle and lamina anatomy. Eur Spine J 20:1921-1927, 2011

23. Meyer D, Meyer F, Kretschmer T, Börm W: Translaminar screws of the axis-an alternative technique for rigid screw fixation in upper cervical spine instability. Neurosurg Rev 35:255-261, 2012

24. Miyata M, Neo M, Ito H, Yoshida M, Miyaki K, Fujibayashi $\mathrm{S}$, et al: Is rheumatoid arthritis a risk factor for a high-riding vertebral artery? Spine (Phila Pa 1976) 33:2007-2011, 2008

25. Neo M, Sakamoto T, Fujibayashi S, Nakamura T: The clinical risk of vertebral artery injury from cervical pedicle screws inserted in degenerative vertebrae. Spine (Phila Pa 1976) 30:2800-2805, 2005

26. Nottmeier EW, Foy AB: Placement of C2 laminar screws using three-dimensional fluoroscopy-based image guidance. Eur Spine J 17:610-615, 2008

27. Ryba L, Cienciala J, Chaloupka R, Repko M, Vyskočil R: [Injury of upper cervical spine.] Soud Lek 61:20-25, 2016 (Czech)

28. Shih YT, Kao TH, Pan HC, Chen HT, Tsou HK: The surgical treatment principles of atlantoaxial instability focusing on rheumatoid arthritis. BioMed Res Int 2015:518164, 2015

29. Sim HB, Lee JW, Park JT, Mindea SA, Lim J, Park J: Biomechanical evaluations of various c1-c2 posterior fixation techniques. Spine (Phila Pa 1976) 36:E401-E407, 2011

30. Singh PK, Garg K, Sawarkar D, Agarwal D, Satyarthee GD, 
Gupta D, et al: Computed tomography-guided C2 pedicle screw placement for treatment of unstable hangman fractures. Spine (Phila Pa 1976) 39:E1058-E1065, 2014

31. Smith JD, Jack MM, Harn NR, Bertsch JR, Arnold PM: Screw placement accuracy and outcomes following O-armnavigated atlantoaxial fusion: a feasibility study. Global Spine J 6:344-349, 2016

32. Taller S, Suchomel P, Lukás R, Beran J: CT-guided internal fixation of a hangman's fracture. Eur Spine J 9:393-397, 2000

33. Tauchi R, Imagama S, Sakai Y, Ito Z, Ando K, Muramoto A, et al: The correlation between cervical range of motion and misplacement of cervical pedicle screws during cervical posterior spinal fixation surgery using a CT-based navigation system. Eur Spine J 22:1504-1508, 2013

34. Tessitore E, Bartoli A, Schaller K, Payer M: Accuracy of freehand fluoroscopy-guided placement of $\mathrm{C} 1$ lateral mass and $\mathrm{C} 2$ isthmic screws in atlanto-axial instability. Acta Neurochir (Wien) 153:1417-1425, 2011

35. Wakao N, Takeuchi M, Nishimura M, Riew KD, Kamiya M, Hirasawa A, et al: Vertebral artery variations and osseous anomaly at the C1-2 level diagnosed by 3D CT angiography in normal subjects. Neuroradiology 56:843-849, 2014

36. Wright NM, Lauryssen C: Vertebral artery injury in C1-2 transarticular screw fixation: results of a survey of the
AANS/CNS section on disorders of the spine and peripheral nerves. J Neurosurg 88:634-640, 1998

37. Yu X, Li L, Wang P, Yin Y, Bu B, Zhou D: Intraoperative computed tomography with an integrated navigation system in stabilization surgery for complex craniovertebral junction malformation. J Spinal Disord Tech 27:245-252, 2014

\section{Disclosures}

Dr. Vajkoczy is a consultant for Aesculap and Ulrich Medical and has received honorarium for talks from BrainLab.

\section{Author Contributions}

Conception and design: Czabanka. Acquisition of data: Czabanka, Haemmerli, Foehre, Arden, Liebig. Analysis and interpretation of data: Czabanka, Haemmerli, Hecht, Woitzik. Drafting the article: Vajkoczy, Czabanka, Haemmerli, Woitzik. Critically revising the article: Vajkoczy, Hecht. Administrative/technical/material support: Czabanka, Foehre, Arden, Liebig, Woitzik. Study supervision: Czabanka.

\section{Correspondence}

Peter Vajkoczy, Department of Neurosurgery, Chartéplatz 1, Berlin 10177, Germany. email: peter.vajkoczy@charite.de. 